\title{
Disseminative Capacity and Knowledge Acquisition from Foreign Partners in International Joint Ventures
}

\author{
Minbaeva, Dana; Park, Chansoo; Vertinsky, Ilan; Cho, Yeon Sung
}

\author{
Document Version \\ Accepted author manuscript \\ Published in: \\ Journal of World Business \\ DOI: \\ 10.1016/j.jwb.2018.03.011 \\ Publication date: \\ 2018 \\ License \\ CC BY-NC-ND
}

Citation for published version (APA):

Minbaeva, D., Park, C., Vertinsky, I., \& Cho, Y. S. (2018). Disseminative Capacity and Knowledge Acquisition from Foreign Partners in International Joint Ventures. Journal of World Business, 53(5), 712-724. https://doi.org/10.1016/j.jwb.2018.03.011

Link to publication in CBS Research Portal

\section{General rights}

Copyright and moral rights for the publications made accessible in the public portal are retained by the authors and/or other copyright owners and it is a condition of accessing publications that users recognise and abide by the legal requirements associated with these rights.

\section{Take down policy}

If you believe that this document breaches copyright please contact us (research.lib@cbs.dk) providing details, and we will remove access to the work immediately and investigate your claim. 


\section{Disseminative Capacity and Knowledge Acquisition from Foreign Partners in International Joint Ventures}

\section{Dana Minbaeva, Chansoo Park, llan Vertinsky, and Yeon Sung Cho}

Journal article (Accepted manuscript*)

\section{Please cite this article as:}

Minbaeva, D., Park, C., Vertinsky, I., \& Cho, Y. S. (२०18). Disseminative Capacity and Knowledge Acquisition from Foreign Partners in International Joint Ventures. Journal of World Business, 53(5), 712-724. D0l: 10.1016/j.jwb.2018.03.011

DOI: 10.1016/j.jwb.2018.03.011

* This version of the article has been accepted for publication and undergone full peer review but has not been through the copyediting, typesetting, pagination and proofreading process, which may lead to differences between this version and the publisher's final version AKA Version of Record.

Uploaded to CBS Research Portal: May 2019

(C) 2019. This manuscript version is made available under the CL-BY-NC-ND 4.0 license http://creativecommons.org/licenses/by-nc-nd/4.0/ 


\section{Disseminative capacity and knowledge acquisition from foreign partners in international joint ventures.}

\section{Dana Minbaeva ${ }^{1}$, Chansoo. Park ${ }^{2}$, Ilan Vertinsky ${ }^{3}$ and Yeon Sung Jacob Cho ${ }^{4}$}

${ }^{1}$ Department of Strategic Management and Globalization, Copenhagen Business School, Copenhagen, Denmark. Tel: 45-3815-2527. Email: dm.smg@cbs.dk

${ }^{2}$ Faculty of Business Administration, Memorial University of Newfoundland, St. John's, NL, Canada. Tel: 1-709-864-7937. Email: cpark@ mun.ca

${ }^{3}$ Sauder School of Business, The University of British Columbia, Vancouver, BC, Canada. Tel: 1-604-822-3886. Email: ilan.vertinsky@ sauder.ubc.ca

${ }^{4}$ Business Administration Dept. International Trade, DukSung Women's University. Tel: 82-2901-8547. Email oakright3927@ ds.ac.kr

Acknowledgement: This research was supported by the Social Sciences and Humanities Research Council of Canada (Grant No. 430-2016-00240). 


\title{
Disseminative capacity and knowledge acquisition from foreign partners in international joint ventures
}

\begin{abstract}
We developed a theoretical model that examines the impacts of a foreign parent's disseminative capacity on knowledge transfer to International Joint Ventures (IJVs). We tested our model with data from 199 IJVs in South Korea. We found empirical support for our arguments that the foreign parent firm's codification and articulation ability, willingness to share knowledge, and frequent and effective use of communication channels determined the extent of knowledge acquisition by the local IJV partners.
\end{abstract}

Key words: Disseminative capacity, International Joint Venture, Knowledge Acquisition, South Korea 


\section{Introduction}

Evidence suggests that although international joint ventures (IJVs) provide an optimal governance structure for inter-firm knowledge transfer (Kogut, 1988; Makino \& Beamish, 1998), it is not always effective (Lane, Salk, \& Lyles, 2001; Pak, Ra, \& Lee, 2015). Despite the importance of knowledge transfer for IJV performance (Lane \& Lubatkin, 1998; Simonin, 1999a; Bresman, Birkinshaw, \& Nobel, 1999), knowledge transfer from foreign parent firms is not uniformly effective because of cross-cultural differences (Lyles \& Salk, 1996; Mowery, Oxley, \& Silverman, 1996), knowledge characteristics (Bresman et al., 1999; Simonin, 1999a;

Subramanian \& Venkatraman, 2001), partner opportunism (Kale, Singh, \& Perlmutter, 2000), goal divergence (Park \& Vertinsky, 2016; Doz, 1996), differences in absorptive capacities (Cohen \& Levinthal, 1990; Lane et al., 2001), and governance issues (Makhija \& Ganesh, 1997). In this line of research, the knowledge recipients' (i.e. local employees') lack of sufficient absorptive capacity is one of the primary explanations given in the literature for the high prevalence of ineffective knowledge acquisition by local firms (see e.g. Lane et al., 2001; Lane \& Lubatkin, 1998; Lucas, 2006; Mowery et al., 1996; Anh, Baughn, Hang, \& Neupert, 2006). However, some researchers have pointed out that focusing solely on the absorptive capacity of knowledge recipients will not provide the complete picture, as "all knowledge transfer events involve both a source, or transferor, and a recipient, or transferee" (Martin \& Salomon, 2003, p. 363). Accordingly, in addition to 'capacity to learn' (absorptive capacity), the degree of knowledge acquisition from foreign partners in the context of IJVs is also dependent upon the foreign firm's capacity to teach (Easterby-Smith, Lyles, \& Tsang, 2008; Wang, Tong, 
\& Koh, 2004), i.e., their disseminative capacity (Minbaeva \& Michailova, 2004; Minbaeva, 2007).

The disseminative capacity of knowledge senders is a sparsely researched construct compared to the more rigorously researched absorptive capacity of knowledge receivers (Minbaeva, Pedersen, Bjorkman, \& Fey, 2014; Mu, Tang, \& MacLachlan, 2010; Oppat, 2008). To the best of the authors' knowledge, there has not been any empirical research performed on the importance of the foreign parent firm's disseminative capacity for knowledge acquisition in the context of IJVs. Further, our review of the existing, but limited literature on the senders' capacity to transfer knowledge indicates that despite the efforts of prior studies in this field, the concept of 'disseminative capacity' is still largely a 'black box'. While researchers have agreed that disseminative capacity is not a mono-concept but consists of several distinct elements, the nature of those elements and the interrelations between them are largely underexplored. Unpacking the concept of disseminative capacity theoretically, exploring its elements, and explaining the interdependencies among them will allow us to design governance mechanisms to manage disseminative capacity and ultimately improve knowledge acquisition in IJVs. Consequently, both scholars and practitioners have repeatedly called attention to the need for an extensive investigation of the impact of the knowledge-sender's disseminative capacity on knowledge acquisition success, in terms of both conceptual theories and substantial empirical research (Chini, 2004; Oppat, 2008; Minbaeva et al., 2014; Martinkenaite-Pujanauskiene, 2015; Zhou et al., 2016).

As a first step towards filling this gap, we develop a theoretical framework that identifies three elements of disseminative capacity that are related to the ability, motivation, and 
opportunity of the knowledge senders (Argote, McEvily, \& Reagans, 2003), and clarifies the complex web of interrelationships among them. The three identified elements are: the sender's codification and articulation ability, the sender's willingness to share knowledge, and the sender's propensity to create and use opportunities for knowledge acquisition. We also examine the impact of these interrelationships on the degree of knowledge acquisition achieved by local partners. We then test the theoretical framework in the context of IJVs using data collected from 199 IJVs in South Korea.

Our study makes several contributions. The main contributions to theory include the articulation of the causal linkages among three elements of disseminative capacity and their interrelationships with regards to knowledge acquisition. In doing so, we highlight the sender's role in knowledge acquisition. Specifically, we focus on cross-border transfers of knowledge from foreign firms and evaluate the degree of knowledge acquisition by local partners. Overall, this study makes empirical contributions to the relatively under-researched context of inter-firm knowledge transfer from foreign firms to their local partners in emerging economies (Steensma, Barden, Dhanaraj, Lyles, \& Tihanyi, 2008).

In sections two and three, we develop the theoretical framework and our hypotheses. The fourth section provides details of the methods used in this study, including the procedures used to reduce the risk of common method bias. This is followed by a description of the results. We conclude with a discussion of the implications of our findings for theory and practice.

\section{Theoretical background}


Szulanski (1996) defines knowledge transfer as a process of dyadic exchanges of knowledge between the sender and the receiver, where the effectiveness of knowledge transfer depends on the following determinants: disposition and ability of the sender and recipient, the strength of the tie between them, and "the characteristics of the object that is being created" (Szulanski, 2003: 25). Many conceptual and empirical studies have contributed to the understanding of the determinants of the knowledge acquisition process. Some studies have focused on the characteristics of the transferred knowledge (e.g. Simonin, 1999a, 1999b; Pak \& Park, 2004), while others have looked at the knowledge sources (e.g. Foss \& Pedersen, 2002), absorptive capacity (e.g. Lyles \& Salk, 1996; Lane \& Lubatkin, 1998; Lane et al., 2001; Minbaeva et al, 2003; Pak \& Park, 2004), and the organizational context in which the transfer takes place (e.g. Simonin, 1999a, 1999b; Bresman et al., 1999; Pak \& Park, 2004). Our review of the representative ${ }^{i}$ studies on the determinants of knowledge acquisition showed a major limitation. A disproportional amount of attention was given to the characteristics of the receivers absorptive capacity, while characteristics of the senders - disseminative capacity - was often acknowledged, but seldom properly theorized. Since knowledge transfer is a two-sided process (Argote et al., 2003; Easterby-Smith et al., 2008; Minbaeva et al., 2014), in many situations, the absorptive capacity of the receiver is insufficient for successful knowledge transfer if the sender possesses no disseminative capacity to spread the knowledge (Minbaeva, 2007; Tang, Mu, \& MacLachlan, 2010).

In the literature on inter-firm knowledge transfer (e.g. joint ventures and strategic alliances), a focus on the sender's characteristics is especially crucial (Hamel, 1991; Lyles \& Salk, 1996; Oppat, 2008). Kogut and Zander (1996, p. 503) view a company as "a social 
community specializing in the speed and efficiency of the creation and transfer of knowledge." An extension of this view to an IJV context assumes that the IJV's partners form an extended social community in which the objective of knowledge transfer is a shared norm (Lane et al., 2001). In the context of IJVs, the foreign parent becomes a vital source of both tacit and explicit knowledge (Lyles \& Salk, 1996). Thus, the capacity of the foreign parent to share knowledge with the IJV is an important condition for the effective, speedy transfer of knowledge (Yin \& Bao, 2006).

In the following sub-section, we provide a definition and theoretical foundation for disseminative capacity.

\section{Disseminative capacity: origins and definition}

Disseminative capacity can be viewed as an umbrella term referring to the source's transfer capacity (Martin \& Salomon, 2003); the parent firm's 'capacity to teach' (Easterby-Smith et al., 2008); the characteristics of knowledge source (Szulanski, 1996; Gupta \& Govindarajan, 2000); and so on. Table 1 summarizes key indicators and elements of disseminative capacity that were identified in prior studies and provides an overview of the empirical findings of these studies.

There are several definitions of disseminative capacity assuming various elements (e.g. Szulanski, 1996; Lyles \& Salk, 1996; Gupta \& Govindarajan, 2000; Martin \& Salomon, 2003; Mu et al., 2010) and levels (e.g. individual, organizational). We also noted that theorizations around those elements derive from various streams of literature, such as psychology (given its focus on cognition), economics (given its emphasis on incentives and competition), sociology (given its orientation towards social structure and processes) and teaching (representing a 
professional view of knowledge dissemination). For example, Schulze, Brojerdi and von Krogh (2014), in addition to relying on the literature on knowledge transfer in strategic alliances, also incorporated in their research insights from the literature on teaching (for a detailed review, see Table 2 in Schulze et al., 2014). Teaching (or knowledge dissemination) is regarded in that literature as an individual-level activity that aims to increase students' comprehension and application of taught knowledge. Accordingly, Schulze et al. (2014) define disseminative capacity as "the ability of knowledge holders to convey knowledge in a way that a recipient can comprehend it and put it into practice" (p. 87). Joshi, Sarker and Sarker (2007), following Szulanski (1996), build upon insights from communication theory - a mathematical theory of communication (Shannon \& Weaver (1949), Schramm's (1971) theory of mass communication, and Berlo's (1960) communication model, defining disseminative capacity in terms of the sender's (cognitive) capability, credibility and communication extent. Minbaeva and Michailova (2004) draw an analogy from the absorptive capacity literature and emphasize behavioral elements of disseminative capacity (specifically, ability and willingness to share knowledge).

Insert Table 1 here

What is noticeable is that despite the variety of conceptualizations, there is a common recognition that disseminative capacity is not a mono-concept, but consists of several distinct elements. In this paper, and in line with Argote, McEvily \& Reagans' (2003) classification of ability, motivation, and opportunity as the three key mechanisms of knowledge transfer (see also Chang, Gong, \& Peng, 2012), we conceptualize disseminative capacity as a combination of the sender's ability to codify and articulate knowledge, the sender's willingness to share knowledge, 
and the sender's propensity to create and use opportunities for knowledge acquisition by the receiver. Consistent with the previous research, we argue that the sender's ability is a necessary but insufficient condition for successful knowledge acquisition by local partners.

Clearly, knowledge senders must have the ability to engage in knowledge sharing if a knowledge transfer is to be successful (Minbaeva \& Michailova, 2004; Chang et al., 2012). Szulanski (1996) suggests that the success of knowledge sharing partly depends on how the communication gap between the knowledge sender and the knowledge receiver is bridged. Knowledge senders who possess extensive, diverse knowledge are presumably better able to share their knowledge because they are more able to understand how their knowledge may be valuable; therefore, they are potentially better able to frame the knowledge in a way that is pertinent to the potential knowledge receiver (Reagans \& McEvily, 2003). However, this potential remains unrealized if knowledge senders do not have a willingness to share their knowledge, and/or are unable to create and use opportunities to do so (Chang et al., 2012; Minbaeva et al., 2014).

In the context of the IJV, the willingness of the foreign parent firm to cooperate is influenced by the original motive for establishing the joint venture. When deciding to establish joint ventures, partners typically expect to benefit from complementary resources and improve their efficiency (Hau \& Evangelista, 2007). Access to complementary knowledge resources is often a prime motive for entering into a joint venture (Kogut, 1988; Inkpen \& Beamish, 1997). Despite these potential benefits, parent firms may be less willing to share their knowledge with the IJV, as there is a risk that the competitive value of (tacit) knowledge will erode in such situations (Inkpen, 2000). In fact, partner protectiveness (Simonin, 1999a; 1999b) is borne of a 
complex mixture of fears, including concerns about the disruption of the status quo in a relationship, the shifting of bargaining power between the involved firms, potential loss of ownership, and the loss of a firm's relative position of privilege in a relationship (Hau \& Evangelista, 2007; Inkpen, 2000).

Similarly, Hamel, Doz \& Prahaland (1989) have investigated how companies use alliances to enhance their internal skills and technologies while guarding against the transfer of competitive advantages to ambitious partners. Competitive learning is often regarded a primary benefit from international collaborations (Hamel, 1991). As a result, partners may be less willing to share knowledge, trying to limit transfers of knowledge that may erode their competitive advantages ${ }^{\mathrm{ii}}$. Unless they developed strong trust in their partners or have a legal and governance structure in place that provides them with a protection of their proprietary knowledge, partners are likely to view the alliance as a race to learn (Hamel, 1991). Without strong trust, a careful partner selection process, and/or effective governance structure that ensure intellectual property protection or a narrow alliance scope that minimizes exposure, mechanisms that safeguard partners' proprietary knowledge, are needed to maintain willingness of partners to share knowledge. (Li, Eden, Hitt \& Ireland, 2008).

However, knowledge transfer cannot occur without an opportunity to transfer knowledge (Ghoshal \& Bartlett, 1988). Argote et al. (2003) argue that "ability and extra effort are even more valuable when coupled with opportunity ... to create, retain and transfer knowledge" (p. 575). In other words, the sender's willingness and ability must be augmented with the active creation of concrete opportunities to transfer knowledge, such that both the physical and psychological distances between organizations shrink (Argote et al., 2003). This means that organizations must 
create opportunities for frequent interaction. Therefore, we explicitly consider not only the capacity of the sending organization to articulate, codify and communicate knowledge, but also the opportunities that are created for interaction between the firms.

In the next section we hypothesize about the relationships between the elements of disseminative capacity presented above and their impact on knowledge acquisition in the context of IJVs.

\section{Hypotheses development}

\subsection{Foreign parent's ability to codify and articulate knowledge}

Valuable knowledge is often of a tacit nature. Effective transferring of tacit knowledge often demands teaching (Winter, 1987). Therefore, among other traits, knowledge senders should have well-developed abilities to codify and communicate knowledge. Hence, the effectiveness of knowledge acquisition depends on the ability of the senders to articulate his/her knowledge in a way that the receivers can understand (Minbaeva, 2007). This ability of the sender is related to their previous experiences and their capability to frame knowledge in different ways and consider different perspectives (Reagans \& McEvily, 2003).

Further, knowledge is often created and developed in a particular setting in forms that reflect the distinct context of these settings, to be accessible in other settings, it must first be detached from its original setting, and standardized or de-contextualized (Oppat, 2008). Knowledge must also be made relevant to the applications envisaged for it in its new setting

(Raab, Ambos \& Tallman, 2014). These transformation processes, which are known as the articulation and codification processes, encompass the alienation of knowledge from its implicit 
knowledge source, and its transformation into an explicit form which is to be formally and systematically transmitted between firms (Kogut \& Zander, 1992; Nonaka, 1994; Pak et al., 2015).

Knowledge senders tend to articulate knowledge of their field in an abstract way or in a way that reflects their own context, which makes it difficult for novice recipients to understand and apply the knowledge in practice (Carlile \& Rebentisch, 2003). Hence, to improve the effectiveness of knowledge acquisition, knowledge senders must develop an ability to assess the needs of recipients. They must also be able to customize the articulation and codification processes using a language that the receivers can understand, so that they can interpret and match the knowledge to their specific needs and environment (Nonaka, 1994; Reagans \& McEvily, 2003). Therefore, in line with the extant literature, we propose:

H1. In the context of IJVS, the higher the foreign partner's ability to codify and articulate knowledge, the higher the extent of knowledge acquisition by the local partner.

In addition to the above, we argue that the extent of knowledge acquisition by the local IJV partner is further influenced by three mediating relationships that concern the foreign parent's willingness to share knowledge and the creation and use of opportunities for knowledge sharing by the foreign parent.

\subsection{Foreign parent's willingness to share knowledge}

As discussed in the previous section, the sender's willingness to transfer knowledge plays a crucial role in knowledge acquisition by local IJV partners. We expect the relationship between the foreign partner's ability to codify and articulate knowledge and the extent of knowledge 
acquisition by local partners to be mediated by the foreign partner's willingness to share knowledge.

There is a general consensus among theoretical and conceptual researchers that a strong willingness on behalf of knowledge senders to share their knowledge increases the likelihood of a successful knowledge acquisition by the recipients (Szulanski, 1996; Simonin, 1999a; Gupta \& Govindarajan, 2000). Szulanski (1996) assumes that certain characteristics of a knowledge source, such as a lack of motivation and being perceived as unreliable, are among the factors that restrict knowledge transfer. But, Simonin (1999a) found that the willingness of external sources to fully cooperate in knowledge transfer (low partner protectiveness) had a non-significant effect on the outcomes of knowledge transfer. According to Simonin (1999a), however, this finding may be due to such elements as biased answers, difficulties in detecting or observing the phenomena, or the partners' opportunistic behavior. Gupta and Govindarajan (2000) hypothesize that the motivational disposition of knowledge senders has a positive impact on the magnitude of knowledge inflow and outflow. They operationalize this construct in terms of the network vs. subsidiary focus of the incentive system for the subsidiary president. However, their results do not provide much support for their prediction. They suggest two possible explanations. First, the motivational disposition to share knowledge may depend on variables other than the CEO's incentive system. Second, the receivers' motivation to acquire knowledge may be more important than the motivation of the senders.

Notwithstanding the important role of motivation as independent explanans of knowledge acquisition, we argue that willingness to share knowledge is cognitively generated. It is partly on the basis of the perceived ability to codify and articulate knowledge that foreign partners choose 
which goals and challenges to undertake (Bandura, 1991), how much effort to invest and how long to persevere (Bandura, 1999) in the face of difficulties associated with knowledge acquisition. Strong belief in a firm's own ability to codify and articulate knowledge sought by the local IJV employees will strengthen the senders' willingness to exercise self-influence by goal setting; this provides another major cognitive mechanism for motivation (Locke \& Latham, 1990). As Bandura (1999) explains, "once people commit themselves to values goals, they seek self-satisfaction from fulfilling them and intensify their efforts by discontent with substandard performances ... When faced with obstacles, setbacks and failures those who doubt their capabilities slacken their efforts, give up or settle for mediocre solutions" (p.28). That is, the foreign partner with a high ability to codify and articulate knowledge needed by the local IJV partner will show a greater effort to master the challenges associated with knowledge acquisition and willingness to contribute with new knowledge. The foreign parents with low codification and articulation ability tend to shy away from difficult tasks, have low aspirations, and have weaker commitment to the IJV goals (such as knowledge acquisition). When faced with difficult tasks, these foreign parents will dwell on obstacles, slacken their efforts, or give up quickly in the face of difficulties. To avoid difficulties, they may even become more guarded in their interactions with the IJV and appear hostile towards knowledge sharing (Husted \& Michailova, 2002).

H2. In the context of IJVS, the foreign partner's willingness positively mediates the relationship between the parent's ability to codify and articulate knowledge and the extent of knowledge acquisition by the local partner.

High codification and articulation ability may remain unrealized if the foreign parent does not create opportunities to share knowledge and use those opportunities effectively. In the 
next section we argue that frequency of interaction and effective use of communication channels mediate the relationship between the parent's ability to codify and articulate knowledge and the extent of knowledge acquisition by the local partner.

\subsection{Creation and use of opportunities for knowledge acquisition by foreign parent firms}

Foreign parent firms with higher levels of ability may also be more likely to have the capacity for greater levels of interaction to promote collaboration (Bandura, 1999), leading to more effective knowledge transfer processes. Further, a strong belief in a firm's own ability to codify and articulate knowledge should result in knowledge senders investing in shared-access databases, developing effective communication systems, and generally increasing the frequency of formal and informal interactions and communications between the foreign parents' employees and the IJVs' employees.

Frequent face-to-face interactions enable mutual observation, an important channel through which tacit knowledge is transferred (Nonaka, 1994; Nadler, Thompson, \& Van Boven, 2003). More frequent face-to-face interactions between knowledge senders and knowledge receivers allow for questioning and adaptation, which are key to learning and acquisition. A higher frequency of interactions provides more opportunities for senders to learn about receivers' needs and abilities. It also creates opportunities for informal feedback, which in turn allows senders to adjust, augment and customize their transfers of codified knowledge. Such interactions are often facilitated by inter-firm visits of managers and employees (Minbaeva \& Michailova, 2004), internships, joint training programs, and technical meetings (Bresman et al., 1999; Ghoshal \& Bartlett, 1988). Furthermore, even short-term foreign visits and meetings enable expatriate managers to enhance their teaching skills, competencies, language skills and abilities to 
communicate across cultures (Minbaeva \& Michailova, 2004). The exchange of employees between parent firms and IJVs creates greater openness and closer proximity among their employees, which in turn allows the IJV's employees to gain a greater awareness of 'who knows what'. Such exchanges also create informal opportunities for knowledge transfer through more personal and unstructured channels (Argote et al., 2003).

In sum, foreign parents with higher levels of ability may also be more likely to realize the existing opportunities to promote collaboration (Bandura, 1999), leading to more effective knowledge processes.

H3a. In the context of IJVs, the frequency of interactions between foreign and local IJV partners positively mediates the relationship between the foreign partner's ability to codify and articulate knowledge and the extent of knowledge acquisition by the local partner.

The effective use of multiple communication channels is important in order to avoid misinformation and maintain transparency, especially in long-distance relationships (Bresman et al., 1999). An effective communication system requires the sender to make available a comprehensive set of communication channels, and appropriately select and use those channels in a way that best meets the recipients' needs (Murray \& Peyrefitte, 2007). Bresman et al. (1999) argue that the availability and choice of effective modes of communication are more important determinants of knowledge transfer success than the frequency of communication between the IJV and the managers of the foreign parent firm.

Yet, it is not just the pure existence of communication channels, but rather the use of these channels that matters as far as knowledge acquisition is concerned. The effective use of diverse 
communication channels is especially important when the geographical distance is significant, when there is a gap in the technological capabilities of the senders and receivers, or when the channels are not reliable.

Further, the foreign parents' effective use of these communication channels is most important in determining the extent of knowledge acquisition by the local partner (Minbaeva, 2013). A strong belief in a firm's own ability to codify and articulate knowledge should result in knowledge senders investing in various communication channels, developing effective communication systems, and using those effectively to increase the frequency of formal and informal communications between the foreign parents' employees and the local employees. In sum, the foreign parent's ability to codify and articulate knowledge is related to an increased and more effective use of appropriate channels of communication that in turn leads to higher levels of knowledge acquisition. We therefore posit that:

H3b. In the context of IJVs, the effective use of communication channels by the foreign partner positively mediates the relationship between the foreign partner's ability to codify and articulate knowledge and the extent of knowledge acquisition by the local partner.

\section{Research method}

\subsection{Research setting and sample selection}

The research model was tested using data on a resurveyed sample of Korean IJVs. The original sample (Park, Vertinsky, \& Lee, 2012) provided us with the respondents for the new survey. The participating firms were originally identified through the Foreigner Investment Statistical 
Yearbook (2008) published by the Ministry of Knowledge Economy of the Republic of Korea, which is the most comprehensive directory of foreign direct investment in South Korea, and has been widely used for similar research purposes (Choi \& Beamish, 2004).

After the 1997 Asian financial crisis, South Korea became more open to foreign direct investment (FDI). South Korea's growth opportunities attracted a large number of diverse multinational corporations (MNCs) (Park et al., 2012), which entered the country through joint ventures with local firms. The country's growth in the post-Asian financial crisis period can be partly attributed to successful transfers of knowledge from foreign parents to IJVs, which has led to technological and managerial innovations. Given the importance and success of knowledgetransfer processes and the large number of diverse IJVs in South Korea, the country serves as an appropriate context for the investigation of the process of knowledge transfer from foreign parents to IJVs (Pak \& Park, 2004; Pak et al., 2015).

\subsection{Data collection}

A survey was used to collect the data. Pretesting provided a means of reducing ambiguity and bias in our measurements (Churchill, 1979). We conducted face-to-face interviews and email-based pretests with 10 employees of South Korean multinationals in order to ensure that the survey items would be appropriate for and comprehensible to our target respondents. The survey instrument (a structured questionnaire) was also pretested with international business faculty members at several South Korean universities. Adjustments were made to reflect the feedback received. Where possible, the questionnaire was developed using validated multi-item scales from prior research. We followed a process of translation and back-translation to ensure 
fidelity of the translation to the original scales (Brislin, 1970). The questionnaire was developed in English and translated into Korean, then back-translated into English by a third party.

The typical respondent was a company general manager or an IJV-related manager in South Korea who was in charge of international operations. The respondents completed the questionnaire by a phone interview, mail or fax. We used perceptual measures for the operationalization of all variables. Perceptual measures are generally recommended and widely used in studies on knowledge transfer (Gooderham, Minbaeva, \& Pedersen, 2011). In this paper, we are studying the attributes of knowledge senders. However, instead of asking them to perform a self-assessment or self-evaluation, we rely on the perception of knowledge receivers to evaluate the sender's willingness, the sender's codification and articulation ability and the sender's propensity to create and use opportunities for knowledge acquisition. Analogous measures were used in studies on knowledge receivers' absorptive capacity when knowledge senders (local parents or headquarters of the multinationals) were asked to evaluate the absorptive capacity of knowledge receivers (e.g. Tsang, Nguyen, \& Erramilli, 2004; Pak et al., 2015; Hsu, Iriyama, \& Prescott, 2016). In those studies 'self-assessment' is likely to be more vulnerable to biases such as self-representation. Arguably, the receiver in the context of the IJV can assess more accurately what knowledge originating from the foreign parent was indeed absorbed by its employees. Moreover, some of the learning by the IJV 's employees, occurs through acquisition of tacit knowledge, where learning may not involve planned teaching by foreign employees (who may not be fully aware that they actually 'teach' or transfer tacit knowledge they may not be aware that they possess ) but by the IJV's employees who learn through observation and interaction with the foreign employees. We do, however, acknowledge 
in discussing the limitations of our study, the value of comparing assessments of knowledge transfers from both perspectives (those of senders and those of receivers) and discuss the implications for the interpretation and generalizability of the results.

All respondents had held their positions for at least one year. We received 220 replies, 21 of which were unusable. The response rate was thus 10.51 percent $^{i i i}(220 / 2094)$. The sample included joint ventures active in the following industry groups: retail and distribution (17.6\%), chemical (16.6\%), electronics (13.1\%), transportation (10.1\%), logistics $(9.5 \%)$, business services $(6.5 \%)$, machinery $(7.5 \%)$, metal $(7.0 \%)$, finance and insurance $(1.5 \%)$, and others $(10.6 \%)$. Tables $2 \mathrm{a}$ and $2 \mathrm{~b}$ present the profiles of the IJVs in our sample.

Insert Tables $2 \mathrm{a}$ and $2 \mathrm{~b}$ here

\subsection{Measures}

Scales derived from the literature review were modified to suit the research purpose and the context of this study. The modification of the scales was informed by our interviews of business practitioners and academics in international business.

Knowledge acquisition: We used a six-item scale to measure the local IJV's acquisition of knowledge from their foreign partners. Such knowledge included (1) written management knowledge, (2) procedural or technical manuals, (3) new marketing expertise, (4) knowledge about foreign cultures and tastes, (5) knowledge about managerial practices (Dhanaraj, Lyles, Steensma, \& Tihanyi, 2004), and (6) knowledge acquired through the demonstration of practices and the observation of working processes. The first five items were taken from Dhanaraj et al. 
(2004), while the sixth was created by the authors of this paper following previous measures in the literature (Gupta \& Govindarajan, 2000).

Foreign parents' willingness: The sender's willingness to share knowledge was operationalized using a seven-point Likert scale, which integrated the scales developed by Minbaeva \& Michailova (2004), and Simonin (1999a). Our integrated scale included the following dimensions of intent: (1) willingness, (2) protectiveness (reverse coded), and (3) positive sharing.

Frequency of interactions: In terms of interactive opportunities, respondents were asked to indicate (1) how often the IJV employees visited the foreign parent, (2) how often the IJVs received visitors from the foreign parent, and (3) how often the IJV employees visited the parent liaisons and task forces to coordinate their decisions and actions (Bresman et al., 1999; Gupta \& Govindarajan, 2000).

The use of communication channels: We followed Murray and Peyrefitte (2007) in their method of measuring the use of communication channels. We assess the availability and effective use of the following: (1) teleconferencing, (2) face-to-face meetings, and (3) access a foreign parent employee, who can act as a mentor.

Foreign parents' codification and articulation ability: Articulation and codification ability was measured using three items, indicating the ability of the foreign parent to ensure that: (1) knowledge is contained in manuals, checklists, formal processes, routines, and guidelines (2) resources such as manuals (containing tools, templates, or frameworks) are developed to assist 
the transfer of technical and other knowledge (Kale \& Singh, 2007), and (3) foreign parent employees effectively respond to the feedback from local IJV employees.

To account for the impact of confounding variables that may affect the transfer of knowledge other than those included in our theoretical framework, we included proxies for absorptive capacity often used in the literature (i.e., investment in training \& education, cultural distance, and IJV experience) (Lane et al., 2001; Cohen \& Levinthal, 1990) and other control variables. First, the age of the IJV (a proxy for accumulated experience) was included as a control variable, as more experience is associated with lower knowledge transfer costs and a greater stock of knowledge (Barkema \& Bell, 1996; Cohen \& Levinthal, 1990). IJV age was measured as the number of years the IJV had operated in South Korea.

Second, IJV size is likely to affect knowledge acquisition because it may contribute to organizational inertia and thus inhibit knowledge acquisition (Lane et al., 2001). Larger IJVs may also seek to acquire less knowledge from foreign partners because they are able to generate more knowledge themselves (Minbaeva, Pedersen, Bjorkman, Fey, \& Park, 2003). We measured firm size by the number of IJV employees.

Third, knowledge acquisition may be influenced by ownership structure, as ownership structure is related to the strategic rationale for transferring (or blocking transfers of) knowledge and skills. To control for the effect of ownership structure, this factor was coded as a dummy variable (coded 1 for foreign majority ownership and 0 otherwise) (Lyles \& Salk, 1996).

Fourth, we controlled for national cultural distance using Kogut and Singh's (1988) composite index based on the national cultural dimensions of individualism, power distance, uncertainty, and masculinity of each country. With data from Hofstede's (1997) study, differences in national culture were 
calculated as the absolute difference for each national cultural dimension between partners.

Fifth, we controlled for the effects of geographic distance based upon the number of direct air miles between the country where the IJV was located and the country of the foreign parent firms (Hansen and Løvås, 2004; Ambos \& Ambos, 2009). When there is significant distance between units, the likelihood of interactions decreases, while those that are more closely located have more effective knowledge transfer, with additional increases in motivation and engagement (Ambos and Ambos, 2009; Darr and Kurtzberg, 2000).

Sixth, we controlled for $\boldsymbol{R} \& \boldsymbol{D}$ investment as it is believed to be one of the determinants of knowledge absorption capacity. R\&D activities in a firm not only create knowledge enriching the knowledge base required to absorb transferred knowledge, but also serve as a means of circulating information and knowledge throughout the firm, facilitating the assimilation and application of new knowledge (Cohen and Levinthal, 1989; 1990); We measure R\&D by the R\&D expenditure portion of the total sale revenue (Gupta \& Govindarajan 2000; Park \& Vertinsky, 2016).

Finally, we controlled for industry competition in the local Korean market. Firms in a more concentrated market have less incentive to upgrade their technology and improve their efficiency, as they are not confronted with fierce market competition (Sun, 2011). We used a standard Herfindahl measure (Raghunathan, 1995) concurrent with firm-level local market sales information obtained from the survey. For a given industry with $n$ firms, the Herfindahl measure was calculated as follows: 


$$
\text { Herfindahl }=\sum_{j=1}^{n}\left(\frac{\text { sales }_{j}}{\sum_{j=1}^{n} \text { sales }_{j}}\right)^{2}
$$

\subsection{Common method bias}

A risk of common method variance exists because this study relies on self-reported data from single informants (Podsakoff, MacKensize, Lee, \& Podsakoff, 2003). We used several procedural and statistical remedies (Podsakoff et al., 2003; Lindell \& Whitney, 2001; Podsakoff \& Organ, 1986) to test for possible common bias variance. We performed the procedural remedies of protecting respondent anonymity, reducing survey item ambiguity, and separating scale items. We also applied statistical remedies. We first conducted a Harman's single factor test, where common method bias is indicated by the emergence of a single factor that accounts for a large portion of the variance. Second, we undertook a Lindell-Whitney marker variable test, which uses a theoretically unrelated marker variable (Lindell \& Whitney, 2001). Appendix A summarizes our remedies undertaken against common method bias in detail.

\subsection{Validity \& reliability of measures}

\subsubsection{Measurement Model}

We reviewed the measurement model to confirm that the latent variables were reliable and valid before we tested the hypotheses. Exploratory factor analysis (EFA) using the principal components method and Varimax rotation was applied to identify potentially problematic items and to obtain preliminary indications of unidimensionality. As in Kline (2005), we conducted a number of confirmatory factor analyses (CFAs) to check the measures' convergent and discriminant validity. As shown in Table 3a, the CFA for the 
overall measurement model indicates an acceptable fit (Chi-square $=258.944$; $\mathrm{df}=125$; $\mathrm{NNFI}=0.942 ; \mathrm{CFI}=0.953 ; \mathrm{RMSEA}=0.074)$. All factor loadings are statistically significant at the $5 \%$ level, and all of them exceed the recommended threshold of 0.5 (Fornell \& Larcker, 1981).

To assess the convergent validity of our measurements, we utilized three metrics: the Cronbach's alpha, the composite reliability, and the average variance extracted (AVE) (Fornell and Larcker, 1981) (Table 3b). To assess discriminant validity, we used the methods suggested by Fornell and Larcker $(1981)^{\mathrm{iv}}$. The square root of the average variance extracted (AVE) is greater than all corresponding correlations, which indicates adequate discriminant validity (Table 4$)$.

Insert Tables 3a, 3b, and 4 here

\subsubsection{Structural equation modeling $\&$ goodness of fit}

The structural equation modeling $(\mathrm{SEM})^{\mathrm{v}}$ approach has been used as a preferred method for testing the effects of mediation ${ }^{\mathrm{vi}}$ (Mackinnon, Lockwood, Hoffman, West, \& Sheets, 2002). The significance of the mediation was verified by comparing the fit for the direct link model with that of the predictor-mediator- outcome (Holmbeck, 1997). The hypotheses were tested using AMOS version 20.0. We assessed the entire model using different goodness-of-fit measures including the chi-square value, the RMSEA, the Comparative Fit Index, and the NNFI. 
The results of the mediation tests are presented in Table 5, with Model 4 representing our hypothesized model. Model 4 presents a partial mediation of the effect of codification and articulation ability on knowledge acquisition through the three mediators. M1 is a direct effect model where the four variables (i.e., codification \& articulation ability, foreign parent's willingness, frequency of interactions, and use of communication channel) are directly linked to knowledge acquisition. The fit indices of the direct effect model indicate a somewhat poor fit. M2, the mediating role of foreign parent's willingness was specified, whereby a mediating path through foreign parent's willingness was added to M1. The model fit indices indicate a poor fit. M3 presents an additional mediating path through frequency of interactions, where the link between codification $\&$ articulation ability and frequency of interactions was added to M2. The model fit indices again indicate a poor fit. M4 is a full, partially-mediated model where there is an additional mediating path from codification \& articulation ability to the use of communication channels. M5 represents a complete mediation model where the direct path between codification \& articulation ability and knowledge acquisition was constrained to zero from M4. Compared with the previous models, the overall fit indices of M4 are acceptable and improved ( $\chi 2=489.711$; $\mathrm{df}=268$; $\mathrm{CFI}=0.924 ; \mathrm{RMSEA}=0.065$ ). The RMSEA is only 0.065 , and therefore below the suggested threshold of 0.08. The chi-square difference between models M4 and M5 suggest that model M4 is slightly better than Model $5\left(\Delta \chi^{2}=1.817, \mathrm{df}=1\right)$ based on the critical chi-square value, $\mathrm{p}<0.05$. Model 5 may be preferred since it is more parsimonious than Model 4. Despite this, it would be more conservative to stick with the selection of Model 4 to represent our hypothesized model for further testing, particularly the direct link between codification and articulation ability and knowledge acquisition. We concluded with a choice of Model 4 (partially 
mediated model) as the baseline model for assessment of the hypotheses. The estimates provide robust evidence and demonstrate that the impact of codification and articulation ability on knowledge acquisition is indeed mediated by the foreign parent's willingness, frequency of interactions, and the use of communication channels. Table 5 summarizes the goodness-of-fit statistics for competing specifications of the model.

Insert Table 5 here

\section{Results and discussion}

\subsection{Results}

Figure 1 illustrates the parameter estimates for model M4 (partial mediation). Hypothesis 1 postulates that the ability to codify and articulate knowledge has a direct positive effect on the acquisition of knowledge. As the standardized regression coefficient for the link between codification ability and knowledge acquisition is not significant, Hypothesis 1 is not supported.

Hypothesis 2 posits that foreign parent firms' willingness mediates the impact of the codification and articulation ability on the knowledge acquisition of IJVs. The path from codification and articulation ability to foreign parents' willingness was found to be significant (.684, $\mathrm{p}<0.01)$. The path from foreign parents' willingness to knowledge acquisition was also found to be significant $(.637, \mathrm{p}<0.01)$. Thus, Hypothesis 2 is supported. 
$\mathrm{H} 3 \mathrm{a}-3 \mathrm{~b}$ states that there is an alternative mediating path pertaining to the impact of codification and articulation ability on knowledge acquisition through two dimensions of opportunities. As indicated here, the paths from foreign parents' ability to codify and articulate are significant for both frequency of interactions $(.525, \mathrm{p}<0.01)$ and use of communication channels $(.725, \mathrm{p}<0.01)$. The path from use of communication channels to knowledge acquisition is significant $(.218, \mathrm{p}<0.10)$, but the path from frequency of interactions to knowledge acquisition is not significant. We therefore concluded that Hypothesis $3 \mathrm{~b}$ is supported, and Hypothesis 3a is unsupported.

Insert Figure 1 here

\section{Post hoc analysis}

Puzzled by the results, we further investigated the conditions under which the frequency of interactions between parent firms and IJVs significantly influence knowledge acquisition. Previous research has shown that when IJVs and foreign parents are dissimilar and are based in unrelated industries, the employees of the IJVs may face fundamental communication and perceptual challenges in terms of understanding and acquiring the transferred knowledge. In addition, the IJVs are less likely to understand the value and relevance of the foreign parent firm's knowledge to their businesses, thus making less effort to absorb it. In sum, there is a common assumption in the literature on IJVs that a greater degree of business relatedness can facilitate easier and quicker communication. 
To incorporate the variable of parent and IJV business relatedness into our investigation of the impact of interaction frequency on knowledge transfer, we constructed a measure of relatedness comprised of three items that measure the degree of similarity between the IJV firm and the foreign parent firm along three dimensions. We asked the respondents to describe their opinion regarding relatedness of IJV and foreign parents' business in the following areas: (1) technology, (2) products, and (3) technological skill base (see Barden, Steensma, \& Lyles, 2005). Relatedness was measured as the average of the three ratings. To assess the impact of relatedness, the sample was divided into three groups based on the average scores. Thirty-five percent of the sample ( $\mathrm{N}=70$, less than 4.9) was in the lower group, thirty-nine percent in the upper group $(\mathrm{N}=78$, more than 5.33) and twenty-six percent in the middle group $(\mathrm{N}=51)$. Then we removed the middle group and only compared the high relatedness versus low relatedness group to examine the conditioning effect of relatedness. The remaining sample included 78 high-related and 70 low-related IJVs.

We found that frequency of interactions between IJVs members with higher business relatedness are likely to have a greater positive influence on knowledge acquisition. The magnitude of change in the coefficients for the impact of interactive opportunity on knowledge acquisition in IJVs with higher relatedness scores versus those with lower scores is discernible.

The significant chi-square difference $\left(\Delta \chi^{2}=4.036, \mathrm{P}=0.045\right)$ supports the proposition that relatedness moderates the relationships between interactive transfer opportunities and knowledge acquisition. The coefficient for the link between interactive opportunity and knowledge 
acquisition is positive (0.197) and significant for high-relatedness IJVs, but insignificant and negative (-0.072) for low-relatedness IJVs (see Table 6).

Insert Table 6 here

\subsection{Discussion}

For the past two decades, knowledge has been identified as one of the most important factors in a firm's competitive advantage (Grant, 1996; Kogut \& Zander, 1996). Particularly within IJVs, knowledge acquisition from the foreign firms by the local partners is seen as essential (Lyles \& Salk, 1996; Lane, Salk, \& Lyles, 2001) not only for the survival of IJVs in a competitive market, but also to ensure that IJVs can actively help their parent companies achieve their strategic goals (Berdrow \& Lane, 2003; Pak \& Park, 2004; Wang \& Nicholas, 2005; Ambos \& Ambos, 2009; Evangelista \& Hau, 2009).

In this paper, we investigated the effects of the foreign parent firms' disseminative capacities on the extent of knowledge acquisition by the local IJV partners. Following the lead of Cohen and Levinthal's (1990) seminal paper, the literature on inter-firm knowledge transfer and knowledge acquisition, in particular, emphasizes the role of the knowledge receiver's inadequate absorptive capacity in knowledge-transfer failures. Further developing this perspective, our paper argues that the knowledge acquisition of local IJV partners also depends on characteristics and behaviors (i.e. disseminative capacity) of the foreign parent firms (senders). 
Exploring the concept of disseminative capacity further, we identified three elements associated with the knowledge senders' ability (H1), willingness (H2) and use of opportunity (H3a \& 3b). In particular, we found empirical support for the hypotheses arguing that in addition to a sender's ability to codify and articulate knowledge, the sender's willingness to share knowledge and ability to make effective use of diverse communication channels played an important mediating role for inter-firm transfers of knowledge. This is consistent with Minbaeva and Michailova's (2004) and Minbaeva's (2007) findings that the willingness of the sender to share knowledge is also an important driver of the process of knowledge acquisition (see also Martin \& Salomon, 2003; Easterby-Smith et al., 2008).

Our empirical results show that articulation and codification capabilities do not have a direct impact on knowledge acquisition. A comprehensive portfolio of communication channels that bridges geographical distance is needed when organizations collaborate at a distance. We found that codification and articulation abilities increase the effectiveness of communication channels in use. Indeed, the ability to codify and articulate knowledge may allow customization of the message to enhance its fit with recipient characteristics, thereby bridging knowledge gaps and cultural and institutional distances, and thus potentially increasing knowledge acquisition by the receivers. The use of appropriate communication channels is a general business capability that is necessary for effective inter-firm transfers of knowledge.

Surprisingly, we did not find any support for our hypothesis regarding the impact of frequent interactions on knowledge acquisition, thought interaction frequency was found to be highly significant for knowledge acquisition in many previous studies. We questioned whether the context of our study - the IJVs - has certain underlying characteristics affecting the generic 
findings. In our post hoc analysis we found that in order for frequent interactions to be conducive to knowledge acquisition, high levels of relatedness between senders and receivers are required in terms of products, markets, and business models. Our empirical findings show that frequent interactions, which serve as the main platform for transfers of tacit knowledge, has a significant impact only when senders and receivers share a common prior knowledge base or, at least, a common framework for how they view their business. "If the skills gap between partners is too great, learning becomes almost impossible" (Hamel, 1991: 97). Further, it is accepted that the transfer of tacit knowledge requires the sender's active involvement in the receiver's learning process (Winter, 1987), at least by helping create opportunities for frequent interactions between those in possession of tacit knowledge and those receiving the knowledge. In this regard, the sender must guide the receiver by highlighting opportunities to observe relevant practices and offering direct contacts with potential mentors (Becerra, Lunnan, \& Huemer, 2008; Lane \& Lubatkin, 1998). Without a basic common framework that results from business or technological relatedness, and without recognition of the relevance and potential value of the parent firm's embedded tacit knowledge, interactive opportunities are less likely to result in learning or knowledge acquisition.

Our results have some important implications for future research on knowledge acquisition. The overall findings are interesting given that many researchers have overemphasized the importance of absorptive capacity of knowledge receivers and paid little attention to other determinants of the knowledge acquisition process. Placing emphasis on the behavioral characteristics of knowledge senders, i.e. their disseminative capacity, our findings illuminate the process view of knowledge acquisition as a dyadic exchange of organizational 
knowledge. To advance research on this topic, future studies would need to "shed the past tendency of analyzing one determinant to the exclusion of others" (Hansen \& Lovas, 2004: 820). We encourage researchers to explore potential dynamics between disseminative and absorptive capacities. As Easterby-Smith, Lyles \& Tsang (2008) argue, 'capacity to teach' and 'capacity to learn' can sometimes stimulate or even offset each other. To rephrase Minbaeva et al. (2014), to truly capture absorptive or/and disseminative capacities as a dynamic concept, future research needs to build more on a "it takes two to tango" way of thinking.

The vital role played by the sender's willingness to share knowledge highlights the importance of relational capital - trust, in particular - to the removal of barriers to sharing. An examination of the interplay among trust, commitment to the IJV, and the degree of motivation to share knowledge would be an important and, most likely, fruitful avenue of research. The examination of the economics of knowledge codification and articulation, especially those factors that affect the degree of knowledge customization, presents other theoretical and practical challenges for future research.

Perhaps the most challenging question for future research raised by our results concerns the conditions necessary for the creation of opportunities for knowledge acquisition. Our results indicate that some threshold levels of business relatedness are required to ensure effective creation of interactive opportunities for knowledge acquisition. Within the context of IJVs, partners "must have sufficiently similar knowledge bases and norms in order for the "student" (IJV) to understand the "teacher" (foreign parent)" (Lane et al., 2001: 1140). Alternatively, a key barrier may be the processing of knowledge and its integration with prior knowledge. A refined research framework that includes variables capturing the degree of relatedness between 
knowledge senders and receivers may provide important insights into various opportunities to improve knowledge acquisition by the knowledge receivers.

We find that the identified elements of disseminative capacity are distinct but highly interrelated, thus implying that "they represent different facets of a higher-order construct that commonly underlies them" (Schreiner, Kale, \& Corsten, 2009: 1411). Future research examining possible interdependencies between the identified elements of disseminative capacity may provide interesting insights. While our definition of disseminative capacity as a non-mono concept, consisting of the elements related to the ability, motivation, and opportunity of the knowledge senders, may be applicable for all firms, the specific interrelations suggested in this paper (H2, H3a and H3b) may be only relevant for the context of IJVs, and may be different in established firms, where the opportunity to interact already exist and is in use. So far the interdependencies were only examined amongst the elements of absorptive capacity (the receiver side). For example, in applying the concept of an interaction effect of ability and motivation to the issue of knowledge acquisition, Minbaeva et al. (2003) argue that greater knowledge utilization will be achieved if knowledge receivers have both the ability and the motivation to absorb new external knowledge. Argote et al. (2003) argue that "ability and extra effort are even more valuable when coupled with opportunity ... to create, retain and transfer knowledge" ( $p$. 575). Reinholt, Pedersen, \& Foss (2011) suggest that the extent to which individual employees use the interaction opportunities available in the organization may interact with their motivation to share knowledge. Future research is needed to further unpack the "black-box" of disseminative capacity to understand the complex web of interactions between the identified 
elements of disseminative capacity. Such knowledge will be helpful in identifying governance mechanisms that enable disseminative capacity of foreign partners in the context of IJVs.

The development of a disseminative capacity for knowledge acquisition in IJVs may depend on external environmental factors. In future studies, an investigation of the impacts of national cultures, market structures (e.g., the degree of competition) and other institutional factors (e.g., the nature and quality of the legal systems) on senders' motivations and abilities to share knowledge would facilitate the development of a more comprehensive theory of knowledge acquisition. The same is true for an examination of the effectiveness of the various modes of transferring knowledge in different environmental conditions.

\section{Managerial implications}

The implications of our study for practice are clear. For a local partner to achieve effective knowledge acquisition, the foreign partner must transcend a passive stance where it does not object to knowledge sharing, but does little to facilitate it. The foreign parent firm must evolve into a culture of active sharing. In such a culture, senders are committed to investing in improving their disseminative capacities and actively creating opportunities for knowledge acquisition. Simply having a comprehensive communication channel is not sufficient; rather, it is the effective use of this channel by the knowledge sender that is critical for the active transfer of knowledge; specifically, the codification and articulation ability of the sender must be enhanced by the effective use of this channel.

Frequency of interactions is only relevant for knowledge acquisition when IJV partners have high degrees of relatedness, which can mean they work in a similar business area or have a 
significant overlap in the previous technical knowledge. When relatedness is low, knowledge senders must play a more active role as teachers in the receivers' learning processes. This may involve partial articulation and codification of tacit knowledge in order to provide a sufficient prior knowledge base to enable transfer.

\section{Limitations}

Finally, our study is not without limitations. First, the data were collected only in South Korea, so the results may not be valid more broadly. It is important, therefore, to determine how the South Korean context and the home contexts of the foreign partners in Korean IJVs may influence our findings. South Korea transitioned from a resource poor, low- income country to a technologically advanced high-income one within three decades. It did so partly by adopting outward-looking policies which promoted and supported the acquisition of knowledge from

foreign partners from technologically advanced countries, to improve the competitiveness of Korean firms internationally. Joint ventures with foreign partner firms (IJVs) served as an important mechanism for such knowledge transfers. Korean firms have and continue to place a priority on competitive learning through IJVs. However, differences in national cultures and institutions between Korea and the home countries of partner firms in Korean IJVs may increase the costs of foreign knowledge acquisition by the Korean partners. Korean national culture is a collectivistic and high power-distance culture (Hofstede, 2001) with its communication style being high-context (Hall, 1976; Kim et al., 1998). These characteristics place Korean culture closer to those of Japan and China and more distant from the USA and the EU countries. 
There were 199 firms in our sample from 26 countries (see table 2c). The results of our model estimation showed, however, that cultural distance does not have a significant impact on the acquisition of foreign knowledge by IJVs. A further study we have conducted of the key measures characterizing the knowledge dissemination process compared the averages of 4 clusters of foreign partner firms (Japanese ( $n=95)$, American $(\mathrm{n}=28)$, Europeans $(\mathrm{n}=53)$ and Chinese (China, Hong Kong, Singapore, and Taiwan $(n=14))$, of their codification and articulation abilities, their willingness to share knowledge with the IJV employees and managers, frequencies of interacting with them, the use by the foreign partners of communication channels and the level of knowledge acquired by the IJV from them. Each of the first 3 largest clusters above contained firms with similar home formal institutional environments and geographical distance from Korea. The Chinese cluster contained firms from locations with similar ethnic culture. Nine firms were excluded from the comparisons because they did not fit with any significant cluster of firms. Tests of mean differences revealed, at the 5\% significance level, only one significant difference among all cluster averages. The European cluster had significantly higher codification and articulation abilities than all other clusters. It appears that at least in the context of Korea, differences in foreign partner firms' characteristics and capabilities largely explain the variation in the level of knowledge disseminated from them to their Korean partners, not their home country contexts. It is possible, however, that without the institutionalized drive of Korean firms to learn, and the highly supportive policy environment for corporate learning from foreign companies in Korea, cultural barriers and linguistic difficulties would matter. A multi-country study 
would allow for a closer examination of the impact of external environments in the host country on the knowledge-transfer process.

Second, the study's methodology does not provide sufficient data to capture the specific mechanisms underlying our findings. Future, in-depth case studies of inter-firm transfer processes can enrich our understanding of the interactions between the main and contextual variables, especially with respect to the mechanisms that promote or constrain tacit knowledge acquisition.

Third, as we pointed out earlier, we rely on the perceptions of knowledge receivers (IJVs) in our surveys. We recognized earlier in the paper that the perspectives of the senders and receivers may vary when assessing the process of knowledge dissemination. We have argued that those receiving the knowledge have more opportunities to assess the transfer of knowledge and the barriers they faced in absorbing the knowledge, which includes applying the knowledge in the absence of its senders. Receivers can also report more fully on what they learnt from informal interactions with employees of the foreign firm. We have recognized, however, that incorporating dyadic data into the analysis may reveal other problem areas such as misalignment of expectations and perceptions about the process of knowledge transfer between foreign parent firm managers (teachers) and IJV managers (students) that may constrain the development of disseminative capacity over time. This may present an important opportunity for future empirical research.

Fourth, the data used in this study is cross-sectional. Therefore, no claims of causality can be validated. Moreover, the concept of disseminative capacity — just like absorptive capacity can only be accurately captured in dynamic models (Minbaeva et al., 2014). However, papers 
published on this topic, including our own, are dominated by linear thinking and static models, although such simplification is, perhaps, necessary in order to grasp the basic elements of the concept of disseminative capacity. Future research can aim towards more solid studies of the dynamics that would require longitudinal data.

Limitations aside, we believe our research is timely. As has been argued, to understand knowledge acquisition as a dynamic process, absorptive and disseminative capacities should be viewed as two sides of the same coin, enabling and constraining each other and ultimately, affecting the knowledge acquisition process (Easterby-Smith et al., 2008; Minbaeva et al., 2014).

\section{REFERENCES}

Ambos, T. C., \& Ambos, B. (2009). The impact of distance on knowledge transfer effectiveness in multinational corporations. Journal of International Management, 15(1): 1-14.

Anh, P.T.T., Baughn, C.C., Hang, N.T.M., \& Neupert, K.E. (2006). Knowledge acquisition from foreign parents in international joint ventures: An empirical study in Vietnam. International Business Review, 15(5), 463-487.

Argote, L., McEvily, B., \& Reagans, R. (2003). Managing knowledge in organizations: An integrative framework and review of emerging themes. Management Science, 49(4): 571-582.

Bandura, A. (1991). Social cognitive theory of self-regulation. Organizational behavior and human decision processes, 50(2): 248-287.

Bandura, A. (1999). Social cognitive theory: An agentic perspective. Asian journal of social Psychology, 2(1), 21-41.

Barden, J. Q., Steensma, H. K., \& Lyles, M. A. (2005). The influence of parent control structure on parent conflict in Vietnamese international joint ventures: An organizational justice-based contingency approach. Journal of International Business Studies, 36(2): 156-174.

Barkema, H. G., \& Bell, J. H. J. (1996). Foreign entry, cultural barriers, and learning. Strategic Management Journal, 17(2): 141-166. 
Baron, R. M., \& Kenny, D. A. (1986). The moderator-mediator variable distinction in social psychological research: Conceptual, strategic, and statistical considerations. Journal of personality and social psychology, 51(6), 1173.-1182.

Becerra, M., Lunnan, R., \& Huemer, L. (2008). Trustworthiness, risk and the transfer of tacit and explicit knowledge between alliance partners. Journal of Management Studies, 45(4): 691-713.

Berdrow, I., \& Lane, H.W. (2003). International joint ventures: Creating value through successful knowledge management. Journal of World Business, 38(1): 15-30.

Berlo, D. K. (1960). The process of communication: an introduction to theory and practice. Holt, Rinehart and Winston.

Bresman, H., Birkenshaw, J., \& Nobel, R. (1999). Knowledge transfer in international acquisitions. Journal of International Business Studies, 30(3): 439-462.

Brislin, R. W. (1970). Back-translation for cross-cultural research. Journal of Cross-Cultural Psychology, 1(3): 185-216.

Carlile, P. R., \& Rebentisch, E. S. (2003). Into the black box: The knowledge transformation cycle. Management Science, 49(9): 1180-1195.

Chang, Y. Y., Gong, Y., \& Peng, M. W. (2012). Expatriate knowledge transfer, subsidiary absorptive capacity, and subsidiary performance. Academy of Management Journal, 55(4), 927948.

Chini, T. C. (2004). Effective knowledge transfer in multinational corporations. Basingstoke: Palgrave Macmillan.

Choi, C. B., \& Beamish, P. W. (2004). Split management control and international joint venture performance. Journal of International Business Studies, 35(3), 201-215.

Churchill, G. A. (1979). A paradigm for developing better measures of marketing constructs. Journal of Marketing Research, 16(1): 64-73.

Cohen, W. M., \& Levinthal, D. A. (1990). Absorptive capacity: A new perspective on learning and innovation. Administrative Science Quarterly, 35(1): 128-152.

Darr, E. D., \& Kurtzberg, T. R. (2000). An investigation of partner similarity dimensions on knowledge transfer. Organizational behavior and human decision processes, 82(1), 28-44.

Dhanaraj, C., Lyles, M. A., Steensma, H. K., \& Tihanyi, L. (2004). Managing tacit and explicit knowledge transfer in IJVs: The role of relational embeddedness and the impact on performance. Journal of International Business Studies, 35(5): 428-442. 
Doz, Y. L. (1996). The evolution of cooperation in strategic alliances: Initial conditions or learning processes? Strategic management journal, 17(S1): 55-83.

Dussauge, P., Garrette, B., \& Mitchell, W. (2000). Learning from competing partners: outcomes and durations of scale and link alliances in Europe, North America and Asia. Strategic management journal, 99-126.

Easterby-Smith, M., Lyles, M. A., \& Tsang, E. W. (2008). Inter-organizational knowledge transfer: Current themes and future prospects. Journal of management studies, 45(4), 677-690.

Evangelista, F., \& Hau, L. N. (2009). Organizational context and knowledge acquisition in IJVs: An empirical study. Journal of World Business, 44(1), 63-73.

Fornell, C., \& Larcker, D. F. (1981). Evaluating structural equation models with unobservable variables and measurement error. Journal of Marketing Research, 18(1): 39-50.

Foss, N. J., \& Pedersen, T. (2002). Transferring knowledge in MNCs: The role of sources of subsidiary knowledge and organizational context. Journal of International Management, 8(1), 49-67.

Ghoshal, S., \& Bartlett, C. A. (1988). Creation, adoption, and diffusion of innovations by subsidiaries of multinational corporations. Journal of International Business Studies, 19(3): 365388.

Gooderham, P., Minbaeva, D., \& Pedersen, T. (2011). Governance mechanisms for the promotion of social capital for knowledge transfer in multinational corporations. Journal of Management Studies, 48(1): 123-150.

Grant, R. M. (1996). Toward a knowledge-based theory of the firm. Strategic Management Journal, 17: 109-122.

Gupta, A. K., \& Govindarajan, V. (2000). Knowledge flows within multinational corporations. Strategic Management Journal, 21(4): 473-496.

Hamel, G. (1991). Competition for competence and interpartner learning within international strategic alliances. Strategic Management Journal, 12(S1), 83-103.

Hamel, G., Doz, Y. L., \& Prahalad, C. K. (1989). Collaborate with your competitors and win. Harvard business review, 67(1), 133-139.

Hansen, M. T., \& Løvås, B. (2004). How do multinational companies leverage technological competencies? Moving from single to interdependent explanations. Strategic Management Journal, 25(8-9): 801-822. 
Hau, L. N., \& Evangelista, F. (2007). Acquiring tacit and explicit marketing knowledge from foreign partners in IJVs. Journal of Business Research, 60(11): 1152-1165.

Henseler, J., Ringle, C. M., \& Sarstedt, M. (2015). A new criterion for assessing discriminant validity in variance-based structural equation modeling. Journal of the Academy of Marketing Science, 43(1): 115-135.

Hofstede, G. (1997). Cultures and organizations. New York: McGraw-Hill.

Hofstede, G. (2001). Culture's consequences: Comparing values, behaviors, institutions and organizations across nations (second edition). Sage publications.

Holmbeck, G. N. (1997). Toward terminological, conceptual, and statistical clarity in the study of mediators and moderators: Examples from the child-clinical and pediatric psychology literatures. Journal of consulting and clinical psychology, 65(4): 599-610.

Hsu, S. T. H., Iriyama, A., \& Prescott, J. E. (2016). Lost in Translation or Lost in Your Neighbor's Yard: The Moderating Role of Leverage and Protection Mechanisms for the MNC Subsidiary Technology Sourcing-Performance Relationship. Journal of International Management, 22(1): 84-99.

Husted, K., \& Michailova, S. (2002). Diagnosing and fighting knowledge-sharing hostility. Organizational dynamics, 31(1), 60-73.

Inkpen, A. C. (2000). Learning through joint ventures: A framework of knowledge acquisition. Journal of Management Studies, 37(3): 1019-1044.

Inkpen, A. C., \& Beamish, P. W. (1997). Knowledge, bargaining power, and the instability of joint ventures. Academy of Management Review, 22(1): 177-202.

Joshi, K. D., Sarker, S., \& Sarker, S. (2007). Knowledge transfer within information systems development teams: Examining the role of knowledge source attributes. Decision Support Systems, 43(2), 322-335.

Kale, P., \& Singh, H. (2007). Building firm capabilities through learning: The role of the alliance learning process in alliance capability and firm-level alliance success. Strategic Management Journal, 28(10): 981-1000.

Kale, P., Singh, H., \& Perlmutter, H. (2000). Learning and protection of proprietary assets in strategic alliances: Building relational capital. Strategic Management Journal, 21(3): 217-37.

Kenny, D. A., Kashy, D. A., \& Bolger, N. (1998). Data analysis in social psychology (In D. Gilbert, S. Fiske, \& G. Lindzey (Eds.). The handbook of social psychology (Vol. 1, pp. 233-265). New York: Oxford University Press. 
Khanna, T., Gulati, R., \& Nohria, N. (1998). The dynamics of learning alliances: Competition, cooperation, and relative scope. Strategic management journal, 193-210.

Kline, R. B. (2005). Principles and practice of structural equation modeling, New York: The Guilford Press.

Kogut, B. (1988). Joint ventures: Theoretical and empirical perspectives. Strategic Management Journal, 9(4): 319-32.

Kogut, B., \& Singh, H. (1988). The effect of national culture on the choice of entry mode.

Journal of International Business Studies, 411-432.

Kogut, B., \& Zander, U. (1992). Knowledge of the firm, combinative capabilities, and the replication of technology. Organization Science, 3(3): 383-397.

Kogut, B., \& Zander, U. (1996). What firms do? Coordination, identity, and learning. Organization Science, 7(5): 502-518.

Lane, P. J., \& Lubatkin, M. (1998). Relative absorptive capacity and interorganizational learning. Strategic Management Journal, 19(5): 461-477.

Lane, P. J., Salk, J. E., \& Lyles, M. A. (2001). Absorptive capacity, learning, and performance in international joint ventures. Strategic Management Journal, 22(12): 1139-1161.

Li, D., Eden, L., Hitt, M. A., \& Ireland, R. D. (2008). Friends, acquaintances, or strangers? Partner selection in R\&D alliances. Academy of management journal, 51(2), 315-334.

Lindell, M. K., \& Whitney, D. J. (2001). Accounting for common method variance in crosssectional research designs, Journal of Applied Psychology, 86(1): 114-121.

Locke, E. A., \& Latham, G. P. (1990). A theory of goal setting \& task performance. PrenticeHall, Inc.

Lucas, L. M. (2006). Things are not always what they seem: How reputations, culture, and incentives influence knowledge transfer. Learning Organization, 13(1): 7-24.

Lyles, M. A., \& Salk, J. E. (1996). Knowledge acquisition from foreign parents in international joint ventures: An empirical examination in the Hungarian context. Journal of International Business Studies, 27(5): 877-903.

Mackinnon, D. P., Lockwood, C. M., Hoffman, J. M., West, S. G., \& Sheets, V. (2002). A comparison of methods to test mediation and other intervening variable effects. Psychological methods, 7(1): 83-104. 
Makhija, M. V., \& Ganesh, U. (1997). The relationship between control and partner learning in learning-related joint ventures. Organization science, 8(5): 508-527.

Makino, S., \& Beamish, P. W. (1998). Performance and survival of joint ventures with nonconventional ownership structures. Journal of International Business Studies, 29(4): 797-818.

Martin, X., \& Salomon, R. (2003). Knowledge transfer capacity and its implications for the theory of the multinational corporation. Journal of International Business Studies, 34(4): 356373.

Martinkenaitè-Pujanauskienè, I. (2015). Evolutionary and power perspectives on headquarterssubsidiary knowledge transfer: The role of disseminative and absorptive capacities. Retrieved from BI Brage, the dissertation repository from BI Norwegian Business School.

Minbaeva, D. B. (2007). Knowledge transfer in multinational corporations. Management International Review, 47(4): 567-593.

Minbaeva, D. B., \& Michailova, S. (2004). Knowledge transfer and expatriation in multinational corporations: The role of disseminative capacity. Employee Relations, 26(6): 663-679.

Minbaeva, D. B., Pedersen, T., Björkman, I., \& Fey, C. F. (2014). A retrospective on: MNC knowledge transfer, subsidiary absorptive capacity, and HRM. Journal of International Business Studies, 45(1), 52-62.

Minbaeva, D. B., Pedersen, T., Bjorkman, I., Fey, C., \& Park, H. J. (2003). MNC knowledge transfer, subsidiary absorptive capacity, and HRM. Journal of International Business Studies, 34: 586-599.

Mowery, D. C., Oxley, J. E., \& Silverman, B. S. (1996). Strategic alliances and interfirm knowledge transfer. Strategic Management Journal, 17(1): 77-91.

Mu, J., Tang, F., \& MacLachlan, D. L. (2010). Absorptive and disseminative capacity: Knowledge transfer in intra-organization networks. Expert Systems with Applications, 37(1): 3138.

Murray, S., \& Peyrefitte, J. (2007). Knowledge type and communication media choice in the knowledge transfer process. Journal of Managerial Issues, 19(1): 111-133.

Nadler, J., Thompson, L., \& Van Boven, L. (2003). Learning negotiation skills: Four models of knowledge creation and transfer. Management Science, 49(4): 529-540.

Nonaka, I. (1994). A dynamic theory of organizational knowledge creation. Organization Science, 5(1): 14-37. 
Oppat, K. (2008). Disseminative capabilities: A case study of collaborative product development in the automotive industry. Germany: GablerVerlag.

Pak, Y. S., Ra, W., \& Lee, J. M. (2015). An integrated multi-stage model of knowledge management in international joint ventures: Identifying a trigger for knowledge exploration and knowledge harvest. Journal of World Business, 50(1): 180-191.

Pak, Y. \& Park, Y. (2004). A Framework of Knowledge Transfer in Cross-border Joint Ventures: An Empirical Test of the Korean Context. Management International Review, 44(4): 417-434

Park, C., \& Vertinsky, I. (2016). Reverse and conventional knowledge transfers in international joint ventures. Journal of Business Research, 69(8), 2821-2829.

Park, C., Vertinsky, I., \& Lee, C. (2012). How the Exchange Climate Affects Tacit Knowledge Transfer from Foreign Parents. International Marketing Review, 29(2):151-174.

Pfeffer, J., \& Salancik, G. R. (1977). Organizational context and the characteristics and tenure of hospital administrators. Academy of Management Journal, 20(1): 74-88.

Podsakoff, P. M., MacKensize, S. B., Lee, J.Y., \& Podsakoff, N. P. (2003). Common method biases in behavioral research: A critical review of the literature and recommended remedies. Journal of Applied Psychology, 88(5): 879-903.

Podsakoff, P. M., \& Organ, D. W. (1986). Self-reports in organizational research: Problems and prospect. Journal of Management, 12(4): 531-544.

Raab, K. J., Ambos, B., \& Tallman, S. (2014). Strong or invisible hands?-Managerial involvement in the knowledge sharing process of globally dispersed knowledge groups. Journal of World Business, 49(1): 32-41.

Raghunathan, S.P. (1995). "A refinement of the entropy measure of diversification: Toward definitional and computational accuracy”, Journal of Management, 21(5): 989-1002.

Reagans, R., \& McEvily, B. (2003). Network structure and knowledge transfer: The effects of cohesion and range. Administrative Science Quarterly, 48(2): 240-267.

Reinholt, M., Pedersen, T., \& Foss, N. J. (2011). Why a central network position isn't enough: The role of motivation and ability for knowledge sharing in employee networks. Academy of Management Journal, 24(6): 1277-1297.

Schramm, W., Schramm, W. L., \& Roberts, D. F. (1971). The process and effects of mass communication. University of Illinois Press. 
Schreiner, M., Kale, P., \& Corsten, D. (2009). What really is alliance management capability and how does it impact alliance outcomes and success? Strategic Management Journal, 30(13), $1395-1419$.

Schulze, A., Brojerdi, G., \& Krogh, G. (2014). Those who know, do. Those who understand, teach. Disseminative capability and knowledge transfer in the automotive industry. Journal of Product Innovation Management, 31(1), 79-97.

Shannon, C. E., \& Weaver, W. (1949). The mathematical theory of communication. Urbana, Ill. Univ. Illinois Press.

Simonin, B. L. (1999a). Ambiguity and the process of knowledge transfer in strategic alliances. Strategic Management Journal, 20(7): 595-623.

Simonin, B. L. (1999b). Transfer of marketing know-how in international strategic alliances: An empirical investigation of the role and antecedents of knowledge ambiguity. Journal of International business studies, 30(3): 463-490.

Steensma, H. K., Barden, J. Q., Dhanaraj, C., Lyles, M., \& Tihanyi, L. (2008). The evolution and internalization of international joint ventures in a transitioning economy. Journal of International Business Studies, 39(3): 491-507.

Subramaniam, M., \& Venkatraman, N. (2001). Determinants of transnational new product development capability: testing the influence of transferring and deploying tacit overseas knowledge. Strategic Management Journal, 22(4): 359-378.

Sun, S. (2011). Foreign direct investment and technology spillovers in China's manufacturing sector. Chinese Economy, 44(2), 25-42.

Szulanski, G. (1996). Exploring internal stickiness: Impediments to the transfer of best practice within the firm. Strategic Management Journal, 17(1): 27-43.

Szulanski, G. (2003). Sticky Knowledge: Barriers to Knowing in the Firm. London: SAGE Publications.

Tang, F., Mu, J., \& MacLachlan, D.L. (2010). Disseminative capacity, organizational structure and knowledge transfer. Expert Systems with Applications, 37(3): 1586-1593.

Tsang, E. W., Nguyen, D. T., \& Erramilli, M. K. (2004). Knowledge acquisition and performance of international joint ventures in the transition economy of Vietnam. Journal of International Marketing, 12(2): 82-103.

Wang, P., Tong, T. W., \& Koh, C. P. (2004). An integrated model of knowledge transfer from MNC parent to China subsidiary. Journal of World Business, 39(2), 168-182. 
Wang, Y. \& Nicholas, S. (2005). Knowledge Transfer, Knowledge Replication, and Learning in Non-equity Alliances: Operating Contractual Joint Ventures in China. Management International Review, 45(1): 99-118

Winter, S. (1987). Knowledge and competence as strategic assets. In D. J. Teece (Ed.), The Competitive Challenge: Strategies for Industrial Innovation and Renewal. Cambridge, MA: Ballinger.

Yang, H., Zheng, Y., \& Zaheer, A. (2015). Asymmetric learning capabilities and stock market returns. Academy of Management Journal, 58(2), 356-374.

Yin, E. \& Bao, Y. (2006). The Acquisition of Tacit Knowledge in China: An Empirical Analysis of the 'Supplier-side Individual Level' and 'Recipient-side' Factors. Management International Review, 46(3): 327-348

Zhou, A. J., Fey, C., \& Prashantham, S. (2016). Building disseminative capacity in reverse knowledge transfer. In Academy of Management Proceedings (Vol. 2016, No. 1, p. 16567). Academy of Management. 
Figure 1. Results of analysis on hypothesized relationships

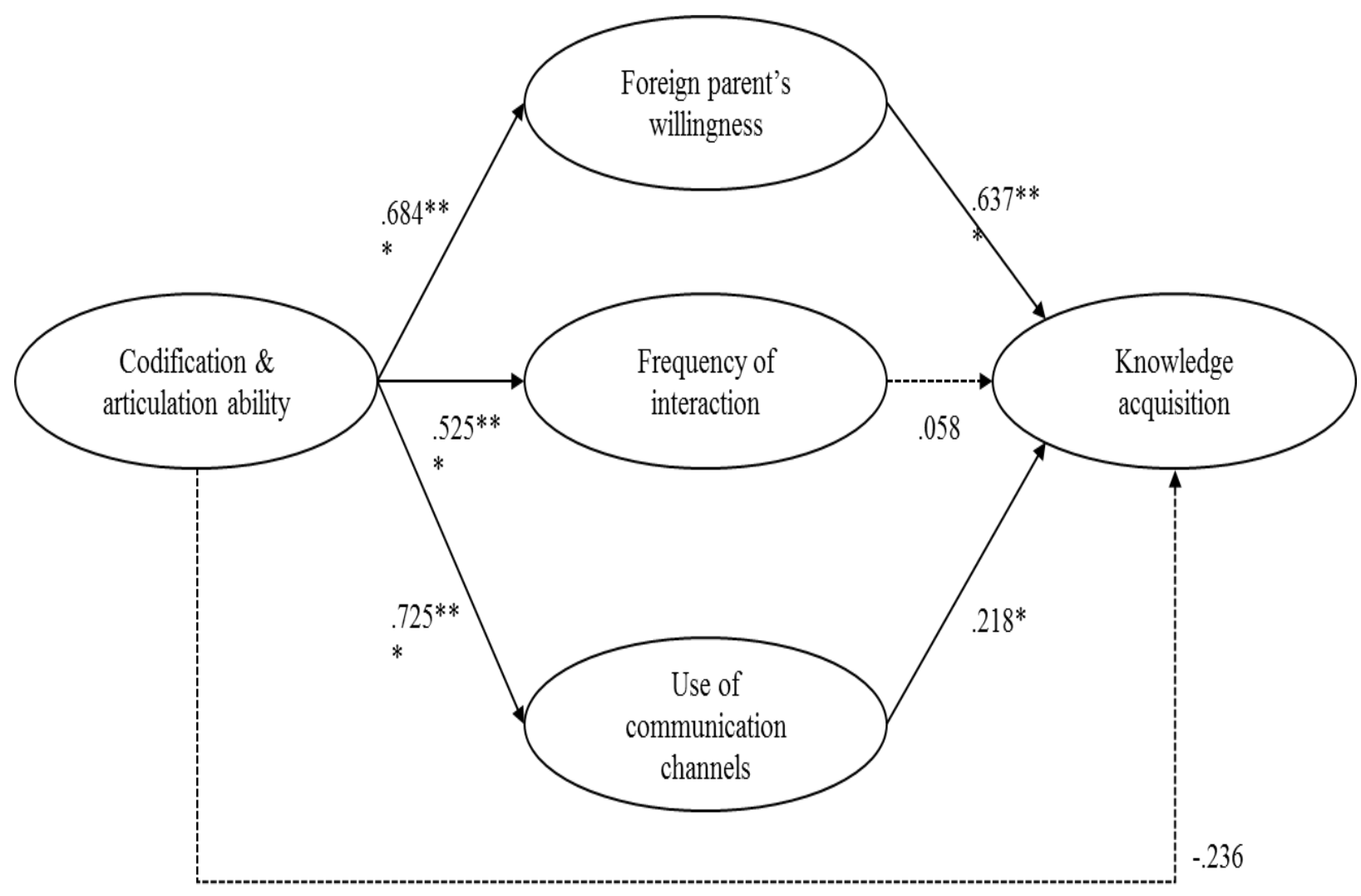

Note: The solid lines represent significant influences. The model estimates are provided from M4 (the tested model). ${ }^{* * *} \mathrm{p}<0.01 ; * * \mathrm{p}<0.05 ;{ }^{*} \mathrm{p}<0.10$

\section{Additional Paths with Control Variables}

\begin{tabular}{llccrr}
\hline To & From & $\begin{array}{c}\text { Standardized } \\
\text { Estimate }\end{array}$ & S.E & C.R & P \\
\hline Knowledge & Age & -.095 & .005 & -1.642 & .101 \\
Knowledge & Size & -.028 & .000 & -.491 & .623 \\
Knowledge & Ownership & -.150 & .004 & -2.586 & .010 \\
Knowledge & Culture & -.070 & .003 & -1.201 & .230 \\
Knowledge & Industry & -.036 & .216 & -.616 & .538 \\
Knowledge & Geo_Distance & .000 & .046 & .000 & 1.000 \\
Knowledge & R\&D Investment & .017 & .009 & .302 & .763
\end{tabular}


Table 1. Disseminative capacity in the studies on organizational knowledge transfer.

\begin{tabular}{|c|c|c|}
\hline Study & Elements of disseminative capacity & Findings \\
\hline \multirow[t]{2}{*}{$\begin{array}{l}\text { Szulanski } \\
(1996)\end{array}$} & $\begin{array}{l}\text { Indicators of knowledge transfer motivation. Source saw benefit in: } \\
\text { measuring its own performance; understanding its own practices; } \\
\text { sharing this understanding with other units; sharing the limits of this } \\
\text { understanding with other units; assessing the feasibility of the } \\
\text { transfer; communicating with recipient; planning the transfer; } \\
\text { documenting practice for transfers; implementing recipient's } \\
\text { support systems; training recipient's personnel; helping recipient } \\
\text { troubleshoot; helping resolve recipient's unexpected problems; } \\
\text { lending skilled personnel }\end{array}$ & $\begin{array}{l}\text { Lack of motivation in the transfer of } \\
\text { knowledge is dominated by other } \\
\text { impediments to the transfer process, } \\
\text { mainly knowledge-related barriers such as } \\
\text { lack of absorptive capacity, causal } \\
\text { ambiguity and the arduousness of the } \\
\text { relationship }\end{array}$ \\
\hline & $\begin{array}{l}\text { Source is perceived as reliable: source and recipient have similar } \\
\text { key success factors; source invented the practice, was the first unit } \\
\text { to have experience and receive practice from other unit; source was } \\
\text { able to accommodate the needs of recipient into practice; source did } \\
\text { not have a hidden agenda; the superior results of the source were } \\
\text { visible; remained stable; source possessed the necessary resources } \\
\text { to support the transfer; source has a history of successful transfers }\end{array}$ & $\begin{array}{l}\text { The impediment of the source being } \\
\text { perceived as unreliable is dominated by } \\
\text { other impediments, mainly knowledge- } \\
\text { related barriers such as lack of absorptive } \\
\text { capacity, causal ambiguity and the } \\
\text { arduousness of the relationship }\end{array}$ \\
\hline $\begin{array}{l}\text { Lyles and } \\
\text { Salk (1996) }\end{array}$ & $\begin{array}{l}\text { Characteristics of activities of the source that indicate effective } \\
\text { knowledge transfer: active involvement of foreign parent (agendas } \\
\text { for knowledge transfer, division of labor, training): the degree to } \\
\text { which the foreign parent contributes to the IJV in managerial and } \\
\text { technical know-how; extent to which the foreign parent provides the } \\
\text { technology while the domestic parent provides the manufacturing } \\
\text { capability; the extent to which the foreign parent provides education } \\
\text { and training to domestic managers }\end{array}$ & $\begin{array}{l}\text { Involvement of the foreign parent in terms } \\
\text { of an explicit division of contributions was } \\
\text { consistently important as indicators of } \\
\text { knowledge acquisition. }\end{array}$ \\
\hline $\begin{array}{l}\text { Simonin } \\
(1999 a,\end{array}$ & $\begin{array}{l}\text { Partner protectiveness of its knowledge resources: partner has } \\
\text { intentional routines and policies to restrict the sharing of relevant }\end{array}$ & Insignificant \\
\hline
\end{tabular}




\begin{tabular}{|c|c|c|}
\hline 1999b) & $\begin{array}{l}\text { information concerning its technology/process know-how; partner is } \\
\text { very protective of its technology/process know-how }\end{array}$ & \\
\hline $\begin{array}{l}\text { Gupta and } \\
\text { Govindarajan } \\
(2000)\end{array}$ & $\begin{array}{l}\text { Motivational disposition of the source unit: incentive focus of a } \\
\text { subsidiary president }\end{array}$ & Insignificant \\
\hline $\begin{array}{l}\text { Martin and } \\
\text { Salomon } \\
(2003)\end{array}$ & $\begin{array}{l}\text { Source transfer capacity: the ability of a firm to articulate uses of its } \\
\text { own knowledge, assess the needs and capabilities of the potential } \\
\text { recipient thereof, and transmit knowledge so that it can be put to use } \\
\text { in another location. }\end{array}$ & Conceptual paper \\
\hline $\begin{array}{l}\text { Minbaeva } \\
\text { and } \\
\text { Michailova } \\
\text { (2004) }\end{array}$ & $\begin{array}{l}\text { Disseminative capacity: the ability and the willingness of } \\
\text { organizational actors to transfer MNC knowledge where and when } \\
\text { it is needed in the organization. }\end{array}$ & $\begin{array}{l}\text { The ability of knowledge senders to } \\
\text { transfer knowledge had a strong positive } \\
\text { effect on the degree of knowledge } \\
\text { acquisition. The effect of knowledge } \\
\text { senders' willingness on knowledge } \\
\text { acquisition was in the expected direction } \\
\text { but insignificant. }\end{array}$ \\
\hline $\begin{array}{l}\text { Easterby- } \\
\text { Smith, Lyles } \\
\text { and Tsang } \\
(2008)\end{array}$ & $\begin{array}{l}\text { Motivation to teach: the lack of motivation to teach may dampen the } \\
\text { enthusiasm for learning }\end{array}$ & Conceptual paper \\
\hline $\begin{array}{l}\text { Mu, Tang } \\
\text { and } \\
\text { MacLachlan } \\
(2010: 33)\end{array}$ & $\begin{array}{l}\text { The ability of people to efficiently, effectively, and convincingly } \\
\text { codify, articulate, \& communicate, spread knowledge in a way that } \\
\text { other people can understand accurately, and finely, tactically put } \\
\text { learning into practice. }\end{array}$ & $\begin{array}{l}\text { Absorptive capacity and disseminative } \\
\text { capacity either interactively or separately } \\
\text { determine how knowledge flows or is } \\
\text { transferred effectively and efficiently } \\
\text { between members of intra-organization } \\
\text { networks }\end{array}$ \\
\hline $\begin{array}{l}\text { Schulze, } \\
\text { Brojerdi and } \\
\text { von Krogh } \\
(2014)\end{array}$ & $\begin{array}{l}\text { The source firm's concerted, collective activities of diffusing } \\
\text { knowledge to the partnering firm with the aim of transferring the } \\
\text { knowledge needed for a successful R\&D alliance. }\end{array}$ & $\begin{array}{l}\text { There is a positive relationship among } \\
\text { attainment of expert knowledge, } \\
\text { assessment of recipient knowledge, and } \\
\text { ability to encode and knowledge transfer } \\
\text { success. }\end{array}$ \\
\hline
\end{tabular}


Table 2a. Demographic characteristics of sample firms $(n=199)$

\begin{tabular}{lccc}
\hline & Min. & Max. & Mean \\
\hline IJV age (years) & 6 & 43 & 16.7 \\
IJV size (total employees) & 2 & 1,715 & 153.2 \\
\hline
\end{tabular}

Table 2b. Sample firms by industry $(n=199)$

\begin{tabular}{ll}
\hline Industry & No. of firms \\
\hline Metal & 14 \\
Machinery & 15 \\
Retail \& Distribution & 35 \\
Business Services & 13 \\
Transportation & 20 \\
Logistics & 19 \\
Chemical & 33 \\
Electronics & 26 \\
Finance \& Insurance & 3 \\
Other & 21 \\
\hline Total number of firms & 199 \\
\hline
\end{tabular}

Table 2c. Country of origin of foreign parent firms $(n=199)$

\begin{tabular}{llc}
\hline Continent & Country & No. of firms \\
\hline \multirow{2}{*}{ Europe } & Austria & 1 \\
& Finland & 1 \\
& France & 12 \\
\hline
\end{tabular}




\begin{tabular}{|c|c|c|}
\hline & Germany & 17 \\
\hline & Ireland & 1 \\
\hline & Luxemburg & 2 \\
\hline & Netherlands & 8 \\
\hline & Norway & 3 \\
\hline & Poland & 1 \\
\hline & Sweden & 2 \\
\hline & Switzerland & 2 \\
\hline & UK & 3 \\
\hline \multirow[t]{8}{*}{ Asia } & China & 5 \\
\hline & Hong Kong & 1 \\
\hline & India & 1 \\
\hline & Japan & 95 \\
\hline & Oman & 1 \\
\hline & Pakistan & 1 \\
\hline & Singapore & 5 \\
\hline & Taiwan & 3 \\
\hline Eurasia & Russia & 1 \\
\hline \multirow[t]{2}{*}{ North America } & Canada & 1 \\
\hline & US & 28 \\
\hline South America & Columbia & 1 \\
\hline Africa & South Africa & 1 \\
\hline Oceania & Australia & 2 \\
\hline Total number of & & 199 \\
\hline
\end{tabular}


Table 3a. Measurement model: standardized parameter estimates

\begin{tabular}{|c|c|c|}
\hline Indicators and Cronbach's alpha & $\begin{array}{l}\text { Standardized } \\
\text { Loading } \\
\text { Estimate }\end{array}$ & $\begin{array}{l}\text { Critical } \\
\text { Ratio }\end{array}$ \\
\hline $\begin{array}{l}\text { Knowledge acquisition (F1): Cronbach's } \alpha=.960 \\
\text { 1. Procedural manuals or technical manuals. } \\
\text { 2. Written knowledge about management techniques. } \\
\text { 3. New marketing expertise. } \\
\text { 4. Knowledge about foreign cultures and tastes. } \\
\text { 5. Managerial practices. } \\
\text { 6. Knowledge acquired through the demonstration of practices and } \\
\text { observation. }\end{array}$ & $\begin{array}{l}.921 \\
.946 \\
.835 \\
.838 \\
.945 \\
.898\end{array}$ & $\begin{array}{l}17.626 \\
18.551 \\
\text { Fixed } \\
14.923 \\
18.520 \\
16.828\end{array}$ \\
\hline $\begin{array}{l}\text { Foreign parents' willingness (F2): Cronbach's } \alpha=.815 \\
\text { 1. The foreign parent is highly willing to transfer new processes and } \\
\text { knowledge. } \\
\text { 2. The foreign parent is very protective of its technology and process } \\
\text { know-how. (reverse coded) } \\
\text { 3. Foreign parent managers and employees are generally positive } \\
\text { about sharing technology and knowledge with the South Korean IJV. }\end{array}$ & $\begin{array}{l}.854 \\
.705 \\
.819\end{array}$ & $\begin{array}{l}\text { Fixed } \\
10.595 \\
12.658\end{array}$ \\
\hline $\begin{array}{l}\text { Frequency of interactions (F3): Cronbach's } \alpha=.877 \\
\text { 1. How often do IJV employees visit the foreign parent } \\
\text { 2. How often do foreign parent employees visit the IJV } \\
\text { 3. How often do IJV employees visit the liaison, temporary task forces } \\
\text { and permanent teams at the foreign parent organization }\end{array}$ & $\begin{array}{l}.958 \\
.953 \\
.621\end{array}$ & $\begin{array}{l}22.508 \\
\text { Fixed } \\
10.433\end{array}$ \\
\hline $\begin{array}{l}\text { The use of communication channels (F4): Cronbach's } \alpha=.839 \\
\text { 1. The foreign parent effectively uses teleconferencing } \\
\text { (e.g., telephone, video, etc.) to communicate with IJV managers. } \\
\text { 2. Foreign parent effectively uses (formal or informal) face-to-face } \\
\text { meetings to communicate with IJV managers. } \\
\text { 3. IJVs managers can access a foreign parent employee, who can act as a } \\
\text { mentor. }\end{array}$ & $\begin{array}{l}.818 \\
.847 \\
.738\end{array}$ & $\begin{array}{l}10.739 \\
10.986 \\
\text { Fixed }\end{array}$ \\
\hline $\begin{array}{l}\text { Codification and articulation ability (F5): Cronbach's } \alpha=.698 \\
\text { 1. The knowledge that is needed from the foreign parent is contained } \\
\text { in manuals, checklists, formal processes, routines, and guidelines. } \\
\text { 2. Resources such as manuals (containing tools, templates, or } \\
\text { frameworks) are developed by the foreign firm to assist the transfer of } \\
\text { technical and other knowledge in the IJV. } \\
\text { 3. Foreign parent effectively responds to the feedback from Korean } \\
\text { IJV employees about their knowledge needs. }\end{array}$ & $\begin{array}{l}.739 \\
.556\end{array}$ & $\begin{array}{l}\text { Fixed } \\
7.166\end{array}$ \\
\hline
\end{tabular}


Table 3b: AVE, composite reliability, and Cronbach's alpha

\begin{tabular}{|l|c|c|c|}
\hline & AVE & $\begin{array}{c}\text { Composite } \\
\text { reliability }\end{array}$ & $\begin{array}{c}\text { Cronbach's } \\
\text { alpha }\end{array}$ \\
\hline Knowledge acquisition & .758 & .949 & .960 \\
Foreign parents' willingness & .571 & .799 & .815 \\
Frequency of interactions & .596 & .810 & .877 \\
The use of communication channels & .675 & .861 & .839 \\
Codification and articulation ability & .787 & .916 & .698 \\
\hline
\end{tabular}

Table 4. Correlations of latent constructs and discriminant validity

\begin{tabular}{|c|c|c|c|c|c|}
\hline & 1 & 2 & 3 & 4 & 5 \\
\hline $\begin{array}{l}\text { Foreign parent's } \\
\text { willingness }\end{array}$ & .756 & & & & \\
\hline $\begin{array}{l}\text { Articulation and } \\
\text { codification }\end{array}$ & $.568 * *$ & .887 & & & \\
\hline $\begin{array}{l}\text { Communication } \\
\text { channels }\end{array}$ & $.356^{* *}$ & $.647 * *$ & .822 & & \\
\hline $\begin{array}{l}\text { Frequency of } \\
\text { interactions }\end{array}$ & $.308 * *$ & $.535^{* *}$ & $.468 * *$ & .772 & \\
\hline $\begin{array}{l}\text { Knowledge } \\
\text { acquisition }\end{array}$ & $.605^{* *}$ & $.352 * *$ & $.344 * *$ & $.303^{* *}$ & .871 \\
\hline
\end{tabular}

Note: Diagonal terms (in bold) are square root of the average variance extracted (AVE). Off-diagonal terms are the c orrelations of latent variables. 
Table 5. Goodness-of-fit statistics for three competing specifications of the model

\begin{tabular}{|l|c|c|c|c|c|c|}
\hline \multicolumn{1}{|c|}{$\begin{array}{c}\text { Model and } \\
\text { structure }\end{array}$} & $\boldsymbol{\chi} \mathbf{2}$ & df & $\boldsymbol{\Delta} \mathbf{2}$ & $\mathbf{C F I}$ & NNFI & RMSEA \\
\hline $\begin{array}{l}\text { M1: direct } \\
\text { effect model } \\
\text { Non-mediated }\end{array}$ & 689.835 & 271 & & .856 & .841 & .088 \\
\hline $\begin{array}{l}\text { M2: M1+F5 -> } \\
\text { F2 }\end{array}$ & 601.063 & 270 & 88.772 & .886 & .874 & .079 \\
\hline $\begin{array}{l}\text { M3: M2+F5- } \\
\text { >F3 }\end{array}$ & 566.654 & 269 & 34.409 & .898 & .886 & .075 \\
\hline $\begin{array}{l}\text { M4: M3+F5- } \\
\text { >F4 }\end{array}$ & 489.711 & 268 & 76.943 & .924 & .915 & .065 \\
\hline $\begin{array}{l}\text { M5: direct } \\
\text { path=zero }\end{array}$ & 491.528 & 269 & 1.817 & .924 & .915 & .065 \\
\hline
\end{tabular}

M1 is a direct effect model, where codification \& articulation ability and the three mediators (foreign parent's willingness, frequency of interactions and use of communication channel) are directly linked to knowledge acquisition. M2, the mediating role of foreign parent's willingness was specified, whereby the link from codification \& articulation to foreign parent's willingness was added to M1. M3, additional mediating role (frequency of interactions) was specified, whereby the link from codification \& articulation to frequency of interactions was added to M2. M4, is a full, partially mediated model where there is an additional mediating path from codification \& articulation ability to the use of communication channels.M5 represents a complete mediation model where the direct path between codification \& articulation ability and knowledge acquisition was constrained to zero from M4.

Table 6. Multi-group path analysis of the moderating effects of knowledge relatedness

\begin{tabular}{|c|l|c|c|c|}
\hline \multirow{2}{*}{ From } & \multirow{2}{*}{ To } & $\begin{array}{c}\text { High } \\
\text { relatedness } \\
(\mathbf{N}=\mathbf{7 8})\end{array}$ & $\begin{array}{c}\text { Low } \\
\text { relatedness } \\
(\mathbf{N}=\mathbf{7 0})\end{array}$ & $\begin{array}{c}\text { Univariate } \\
\text { chi-square difference }\end{array}$ \\
\cline { 3 - 5 } & & Estimate & Estimate & \\
\hline $\begin{array}{l}\text { Frequency } \\
\text { interactions }\end{array}$ & $\begin{array}{l}\text { Knowledge } \\
\text { transfer }\end{array}$ & $\mathbf{0 . 1 9 7 * *}$ & -0.072 & 4.036 \\
\hline
\end{tabular}


Appendix A. Remedies undertaken against common method bias

\begin{tabular}{|c|c|}
\hline Procedural & Implementation \\
\hline $\begin{array}{l}\text { Protecting respondent } \\
\text { anonymity }\end{array}$ & $\begin{array}{l}\text { The survey was conducted in a confidential manner to decrease the social desirability effect (Podsakoff et } \\
\text { al., 2003). In our cover letter, we assured complete anonymity to our respondents. }\end{array}$ \\
\hline $\begin{array}{l}\text { Reducing survey item } \\
\text { ambiguity }\end{array}$ & $\begin{array}{l}\text { We conducted face-to-face interviews and email-based pretests with } 10 \text { employees of South Korean } \\
\text { multinationals in order to ensure that the survey items would be both appropriate for and comprehensible to } \\
\text { our target respondents. We then adjusted the questions to improve face } \& \text { content validity based on these } \\
\text { pre-tests. }\end{array}$ \\
\hline Statistical & Implementation \\
\hline $\begin{array}{l}\text { Harman's single factor } \\
\text { test }\end{array}$ & $\begin{array}{l}\text { We conducted a Harman's single factor test, where common method bias is indicated by the emergence of a } \\
\text { single factor that accounts for a large portion of the variance. However, no such single factor emerged. The } \\
\text { first factor accounted for } 10.5 \% \text { of the } 77.7 \% \text { explained variance. }\end{array}$ \\
\hline
\end{tabular}


i Studies that consider the determinants of knowledge acquisition

ii The tension in alliances between collaboration and competition, that underlies the willingness to share knowledge, has been the subject of a large number of studies since the publication of Hamel et.al.(1989) and Hamel (1991). These studies investigate different antecedents of competitive learning, such as asymmetric learning capabilities (Yang, Zheng, \& Zaheer, 2015), ratio between private and common interests (Khanna, Gulati, \& Nohria, 1998), and knowledge similarities of partners (Dussauge, Garrette \& Mitchell, 2000).

${ }^{\text {iii }}$ We conducted non-response bias test using out-of-sample data. Using the dataset (2008), we collected nonresponding firms' information on ownership structure and sales revenue. We then compared the nonrespondents with the respondents. Independent t-tests were performed on these variables. No significant difference was identified. Hence, non-response bias did not present a problem in our data.

${ }^{\text {iv }}$ The Fornell-Larcker approaches do not reliably detect a lack of discriminant validity in cross-sectional survey studies (Henseler, Ringle, \& Sarstedt, 2015). Henseler et al., (2015) proposed a new technique based on the multitrait-multimethod matrix (HTMT) ratio, which is able to address the discriminant validity. The results reveal that all $\mathrm{CI}$ are between $2.5 \%$ and $97.5 \%$, indicating that there is no discriminant validity problem in the study.

${ }^{v}$ Our study, as many strategy and IB studies that use primary data, involves a cross sectional design. The SEM framework that is often used in such cases does not test for causality directly. The causality inference for the dyadic relationships in the models is based only on strong theoretical arguments underpinning them, as the empirical data reflects only the strength and nature (sign) of the associations between variables. Nevertheless, the SEM framework allows for testing empirically alternative models based on different hypothesized causal links between variables, in terms of variety of the validation criteria ( based on their fit with the data).We have considered the use of instrumental variables to test empirically the hypotheses related to specific dyad causality directions. Unfortunately finding the appropriate instrumental variable proved to be infeasible.

${ }^{\mathrm{vi}}$ A mediation effect is established when the strength of the relationship between the predictor and the outcome is significantly reduced when the mediator is added (Kenny, Kashy, \& Bolger, 1998; Baron \& Kenny, 1986). 